\title{
Brains, Innovations and Evolution in Birds and Primates
}

\author{
Louis Lefebvre Simon M. Reader Daniel Sol \\ Department of Biology, McGill University, Montreal, Quec., Canada
}

\section{Key Words}

Innovation · Brain evolution - Hyperstriatum ventrale . Neostriatum · Isocortex · Birds · Primates · Tool use · Invasion biology

\begin{abstract}
Several comparative research programs have focused on the cognitive, life history and ecological traits that account for variation in brain size. We review one of these programs, a program that uses the reported frequency of behavioral innovation as an operational measure of cognition. In both birds and primates, innovation rate is positively correlated with the relative size of association areas in the brain, the hyperstriatum ventrale and neostriatum in birds and the isocortex and striatum in primates. Innovation rate is also positively correlated with the taxonomic distribution of tool use, as well as interspecific differences in learning. Some features of cognition have thus evolved in a remarkably similar way in primates and at least six phyletically-independent avian lineages. In birds, innovation rate is associated with the ability of species to deal with seasonal changes in the environment and to establish themselves in new regions, and it also appears to be related to the rate at which lineages diversify. Innovation rate provides a useful tool to quantify inter-taxon differences in cognition and to test classic hypotheses regarding the evolution of the brain.
\end{abstract}

Copyright $(2004$ S. Karger AG, Basel

\section{Introduction}

The brain of a crow is larger than that of a dove, while the chimpanzee brain is larger than that of a howler monkey. Comparative neuroanatomists, psychologists and biologists have long been intrigued by the cognitive, life history and ecological traits that might account for this variation in brain size. What are the costs of a large brain and what benefits, if any, does a large brain provide? Does the size of the brain reflect differential cognitive capabilities? Which ecological factors have selected for an increase or a decrease in brain size? Are there phylogenetic constraints that prevent the evolution of large brains in some lineages? What is the influence, if any, of life history traits on the size of the brain? How should we measure and compare relative brain size to address the above questions? Should we focus on whole brains, large areas like the mammalian isocortex and avian hyperstriatum, or more restricted structures such as the hippocampus? How should interspecific cognitive differences be assessed? Is cognition organized into separate 'modules' or is there such a thing as a general problem-solving ability that transcends behavioral domains and different ecological demands?

A variety of comparative research programs (briefly reviewed below) have used different approaches and assumptions to address these and related questions. Here, we focus on one of these programs, a program based on utilizing innovation rate as an operational measure of cognition in birds and primates. Observers of animal behav-

\begin{tabular}{ll}
\hline KARGER & ( ) 2004 S. Karger AG, Basel \\
Fax +4161306 12 34 & \\
$\begin{array}{l}\text { E-Mail karger@karger.ch } \\
\text { www.karger.com }\end{array}$ & $\begin{array}{l}\text { Accessible online at: } \\
\text { www.karger.com/bbe }\end{array}$
\end{tabular}

Louis Lefebvre
Department of Biology, McGill University
1205 avenue Docteur Penfield
Montréal, Québec, H3A 1B1 (Canada)
Tel. +1 514398 6457, Fax +1 514398 5069, E-Mail louis.lefebvre@mcgill.ca 
ior are occasionally struck by the novelty, complexity or unusual nature of the behaviors they witness. In ornithology and primatology, there is a long-standing tradition of publishing such observations, often in the form of short notes. The opening of milk bottles by tits in England [Fisher and Hinde, 1949] and the invention of potato- and wheat-washing by Japanese macaques [Kawai, 1965] are examples of classic field observations that encouraged the development of a new research domain, animal social learning [Zentall and Galef, 1988; Heyes and Galef, 1996; Box and Gibson, 1999; Fragaszy and Perry, 2003]. All other things being equal, we can assume that a species that, for instance, eats more food types, takes advantage of new feeding opportunities and uses more sophisticated food searching and handling techniques will feature in more innovation reports. Thus, by collating large numbers of such observations (currently 2,213 in birds and 533 in primates) and carefully controlling for potential biases, it is possible to quantify taxonomic differences in cognition and behavioral flexibility. It is this measure of the frequency of new, complex and/or unusual behaviors, mostly in the feeding domain, that we have termed innovation rate [Lefebvre et al., 1997; Reader and Laland, 2002]. As an operational definition of cognition in the field, innovation rate allows comparative tests of several classical hypotheses in neurobiology, behavior, evolution and ecology. For example, we discuss below our findings that innovation rate correlates with relative brain size, with individual learning measures, with speciosity, and with invasion success. First, we briefly compare the innovation rate approach with four other comparative programs to show how it can complement these established programs and contribute to our understanding of brain evolution.

\section{Alternative Approaches}

\section{Comparative Psychology}

Comparative psychology is exemplified in the work of such authors as Gossette [1968], Powell [1974], Riddell and co-workers [Riddell and Corl, 1977; Riddell, 1979], Wilson and colleagues [Wilson and Boakes, 1985; Wilson et al., 1985], Sasvàri [1985] and Plowright et al. [1998]. It has mainly focused on associative learning tests presented to a small number (between 2 and 10) of captive species. As summarized by Riddell and Corl [1977], the tests are assumed to measure general abilities for behavioral change in response to novel events. For Macphail [1982; p. 4], 'intelligence ... is held to manifest itself in all those situations in which subjects are required to adapt to novel circumstances'. Contrary to passive observation of animals in the wild, the response to the unnatural demands of captive experiments can reveal the full range of an animal's capabilities, Macphail argues, and these responses are assumed to reflect the way individuals deal with changes in their natural environment. For many authors, taxa with larger brains are presumed to show more of the general ability to respond appropriately to novel events [Gossette, 1968], and in most avian [Gossette, 1968] and mammalian [Riddell and Corl, 1977] species tested, learning performance correlates positively with relative brain size [but see Macphail,1982, 1985; Macphail and Bolhuis, 2001]. For Sasvàri [1979, 1985], urbanization is one situation where novel events occur more rapidly than the norm, and Sasvàri shows that learning rate correlates with degree of urbanization in seven passerine species.

\section{Comparative Biology}

Comparative biology can be illustrated by studies on a number of animal groups, such as primates [CluttonBrock and Harvey, 1980; Dunbar, 1998; Barton, 1999], rodents, insectivores and lagomorphs [Mace et al., 1981], carnivores [Gittleman, 1986; Dunbar and Bever, 1998], bats [Eisenberg and Wilson, 1978], cetaceans [Marino, 1996], birds [Bennett and Harvey, 1985a; Madden, 2001], and fish [Huber et al., 1997]. It uses a much larger sample of species than comparative psychology (as many as several hundred) and focuses on natural history variables that are proposed to correlate with brain size, not tests in captivity. The spectrum of questions addressed is broader than that of comparative psychologists, and in addition to proposed cognitive correlates of brain size, comparative biologists have explored specific life history traits and ecological factors that might help explain the evolutionary diversification of the brain. Many of the studies have looked at feeding ecology and habitat use, but Gittleman [1994] has also examined parental care, Madden [2001] bower building, Iwaniuk et al. [2001] play, while Dunbar and colleagues [Dunbar, 1992, 1995, 1998; Barton and Dunbar, 1997; Dunbar and Bever, 1998; Kudo and Dunbar, 2001], and Marino [1996], have focused on social complexity and group size. In the case of foraging, the assumption is that some strategies require more extensive memory storage than others [Harvey et al., 1980], a greater difficulty of detection, pursuit and manipulation of prey [Gittleman, 1986; Huber et al., 1997], as well as increased sensory and perceptual capacities for locating the food due to its distribution in space and time [Mace et al., 1981]. The food of carnivores, for 
example, is presumed to be more sparsely and less evenly spatially and temporally distributed, and more difficult to detect and capture, than the food of folivores; the distribution of leaves in space and time is also less sparse and more even than that of fruit. Similar assumptions are made for parental care, bower building and group size; larger social groups, for example, are assumed to demand more information storage and processing (to track group members and their relationships), selecting for a 'larger neural computer' [Dunbar, 1998]. By and large, the studies report a positive association between brain size and natural histories that are assumed to be more 'complex': frugivorous, carnivorous or omnivorous feeding (depending on the taxon), larger social groups, monoparental care, more elaborate bowers, more play. In birds, however, relative brain sizes are less easily related to ecological variables when confounding variables are taken into account [Bennett and Harvey, 1985a; Nealen and Ricklefs, 2001], and Bennett and Owens [2002] note that the definitive tests remain to be done.

\section{Comparative Neuroanatomy}

A third approach, comparative neuroanatomy, has focused on the internal architecture of the brain, comparing component volumes in various avian and mammalian taxa. Here, the emphasis tends to be on the brain first and behavior or ecology second. In mammals, Jolicoeur et al. [1984] suggest that variation in relative size of the isocortex is correlated with complexity of the ecological niche. In birds, Rehkämper et al. [1991] assume that the larger relative size of the avian equivalent of the mammalian isocortex, the neostriatum/hyperstriatum ventrale (NeoHV) complex, is the result of strong selection for multimodal integrative capacities and learning, allowing the occupation of a wide spectrum of ecological niches and food types. Rehkämper and Zilles [1991] further postulate a causal relationship between flexible behavior, adaptive ability and an expanded isocortex (in mammals) or NeoHV complex (in birds). Kaas [1995, 2002] notes similarities in the forebrain organization of tree shrews, squirrels, and primates that, he suggests, are due to these animals dwelling in similar niches rather than common ancestry. De Winter and Oxnard [2001] provide a further recent illustration of the comparative neurobiology approach. They identify clusters of unrelated species that occupy similar 'behavioral niches' and have convergently evolved similar brain proportions, and, for example, predict from brain measurements that a particular group of bats should be nectivorous. This prediction was supported by subsequent field observations.

\section{Neuroecology}

The fourth program, termed neuroecology by some commentators [Bolhuis and Macphail, 2001], has focused on rather specialized behavioral domains and localized brain regions. Spatial memory and song learning are the most frequently studied behaviors in this program, researchers examining the links between these behaviors and localized brain areas such as the hippocampus and HVC. The ecological and taxonomic context of the behaviors is much more precise and specialized than it is in the three other approaches. Learned song is predominantly studied in oscines [Nottebohm, 1981; DeVoogd, 2004], whereas food-storing in birds and mammals is the most frequently studied ecological context for spatial memory [Krebs et al., 1989; Sherry et al., 1989; Hampton et al., 1995; Healy and Hurly, 2004], with some work also focusing on brood parasitism in birds [Reboreda et al., 1996], sexually-selected differences in range use in rodents [Jacobs et al., 1990; Jacobs and Spencer, 1994], and foodsearching strategies in lizards [Day et al., 1999a, b]. The assumption here is that large song repertoires [DeVoogd et al., 1993] and storing and retrieval of many food items over long periods [Balda and Kamil, 1989] require a large amount of specialized memory, which is traded-off against memory for other ecological demands [Sherry and Schacter, 1987].

\section{Why Innovation?}

The innovation approach complements and extends the four approaches described above in several ways. Like the first three programs, it focuses on general cognitive abilities rather than specialized ones, as well as large brain areas rather than small, localized structures. Like comparative biology, it looks at hundreds of species in the wild and hence may improve our ability for generalization, but it uses a direct operational measure of cognition in the field, rather than assuming brain size is a correlate of cognitive capacity. In this respect, it is most similar to the neuroecological studies on song repertoire size or the comparative biology of social intelligence, where a direct quantitative estimate of presumed cognitive differences in the field is available: a song thrush Turdus philomelos with 171 songs in its repertoire is assumed to require more memory than a Carolina chickadee Parus carolinensis with 3 [DeVoogd et al., 1993]; a tufted capuchin Cebus apella that interacts with 15 group members is assumed to need to store and process more social information than a woolly lemur Avahi laniger that usually lives in a group of 
two [Dunbar, 1992, 1998; Barton, 1996]. In the comparative psychology, neuroanatomy and biology programs, cognitive differences are not directly quantified in the field, either because cognition is only vaguely defined (e.g. 'complexity of the ecological niche') [Jolicoeur et al., 1984] or because assumptions are made regarding the relative complexities of measurable natural history traits (e.g., frugivory is assumed to have greater memory demands than folivory). Finally, the innovation approach does not depend on captive testing for its assessment of cognitive differences between taxa. Captive tests, which are routinely used for spatial memory or associative learning, are known to be sensitive to contextual variables [Macphail, 1982; Kamil, 1988; Deaner et al., 2000]. The correspondence between a laboratory test and its presumed natural history correlate is also often subject to question. This might be one reason behind the fact that the relationship between degree of food-storing and relative size of the hippocampus in European and North American Paridae and Corvidae [Healy and Krebs, 1992,1996; Hampton et al., 1995; Basil et al., 1996] is stronger than the relationship of either variable with performance in captive tests of spatial memory [GouldBeierle, 2000; Macphail and Bolhuis, 2001].

The advantage of innovation rate is that it is quantitative, direct, taken from field data (for birds), ecologically relevant and available for hundreds of species. Its major drawback is that it is based on chance observations and subject to several potential biases. It shares this drawback with the set of studies on tactical deception by Whiten and Byrne that use a similar quantification of chance observations [Whiten and Byrne, 1988; Byrne and Whiten, 1990; Byrne, 1993; see also open peer commentary following Whiten and Byrne, 1988]. Observations not made as part of an experimental study can easily be characterized, and criticized, as anecdotes. Thorndike [1911] was damning on the use of anecdotes in comparative psychology, noting that 'biologists ... have looked for the intelligent and unusual and neglected the stupid and normal' (p. 25), and his observation that publications are "never about animal stupidity' (p. 22) holds today. Is the amassing of hundreds of 'anecdotes' any superior to drawing conclusions from a single chance observation? We argue that it is, provided (a) suitable steps are taken to ensure the novelty and import of the behavior pattern, and (b) potential confounding variables, such as differences in research effort, are accounted for. We discuss these safeguards below.

Innovation rate is obtained by exhaustive coverage of the descriptive literature, and to date has been compiled for ornithology and primatology only. To attempt to avoid biases during data collection, 'keywords' in the articles such as 'novel', 'never seen before' or 'unusual' are utilized to classify behavior patterns as innovations, so that the decision of whether a particular report qualified as an instance of innovation is made by the author of the article. Innovation rate is thus based on a value judgement by the authors (and sometimes journal editors) of the reports. A typical innovation in birds would be the use by a herring gull Larus argentatus of its normal shell-dropping technique to kill rabbits [Young, 1987] or a usually insectivorous yellowhead Mohoua ochrocephala in New Zealand seen for the first time eating bush lily fruits [Child, 1978]. In primates, typical innovations would be the ring-tailed lemur Lemur catta eating a chameleon [Oda, 1996] or common chimpanzees Pan troglodytes using sticks to walk or sit on as protection against a spiny tree that bears edible fruit and flowers [Alp, 1997]. Further examples are described in Lefebvre et al. [1997, 1998] and Reader and Laland [2001]. For the moment, only feeding innovations have been recorded in birds (with the exception of owls, whose nocturnal habits preclude observations), although Reader and Laland [2002] have collated innovations across all behavioral domains for primates. It is crucial to assume here that the authors of the innovation reports know the normal repertoire of the species they are describing and are correctly identifying what they have witnessed as novel. In the journal British Birds, which publishes a large number of behavior notes from academics and experienced amateur birders (404 of our current data base of 2,213 innovations), an eight member editorial board of ornithologists screens the novelty of the patterns reported. Authors in this journal often refer to an exhaustive published source of avian feeding repertoires, the Handbook of British Birds, and explicitly state that what they have seen is 'not mentioned in the Handbook'. In the harder-to-observe primates, the vast majority of observations are made by experienced field researchers familiar with that species.

In order for innovation rate to be an unbiased measure, data acquisition needs to be systematic and reliable. For birds, the short notes of ornithology journals available to us have been exhaustively examined as far back as 1930 in some geographical zones. Zones with too few journals and too few reports (e.g., Japan) have not been retained for analysis. Five parts of the world, totaling 67 journals, have up to now been subject to analysis: western Europe (current number of innovations $=840$ ); North America $(n=611)$; southern Africa $(n=271)$; the Indian subcontinent $(\mathrm{n}=203)$; and Australasia (Australia: $\mathrm{n}=223$; New Zealand: $n=65$ ). For primates, geographical regions were 
pooled and captive studies included to maximize the size of the data set, resulting in 533 observations of innovation recorded. Inter-observer agreement [Martin and Bateson, 1993] on acceptance of reports is in the 0.8-0.9 range in birds, depending on the study, and 0.8 in primates. In birds, most of the readers doing the exhaustive bibliographic searches are blind to the hypotheses being tested.

Once accepted into the data base, the number of innovation reports for each species is determined and these data are either used in multivariate tests of a hypothesis at this taxonomic level [primates: Reader and Laland, 2002; birds: Sol and Lefebvre, 2000] or at higher taxonomic levels such as the order and parvorder [Lefebvre et al., 1997, 1998]. The multivariate analyses factor out various biases of the innovation measure or suspected confounding variables of the relationship being tested. In studies done at high taxonomic levels, innovation frequency is likely to suffer from biases caused by differences in the number of species per taxon; a parvorder like Passerida, which includes 3,500 species worldwide, is likely to yield more innovation reports than a parvorder like Odontophorida (new world quails) that includes only 6 species. Innovation frequency may also suffer from reporting biases if some species tend to be more studied than others; a highly studied species like the common chimpanzee (with 755 of the 7,144 primate studies listed in the online version of The Zoological Record) is obviously more likely to be observed performing novel behaviors than a poorly studied one like De Brazza's monkey Cercopithecus neglectus (17 articles). In species level analyses and in some parvorder level ones, this reporting bias can be controlled for by including research effort in the multivariate models. Research effort can be estimated by a direct count of the literature or by using the article-count feature of the online version of The Zoological Record. In birds, seven other potential biases have been tested, some originating in the birds themselves, others in the ornithologists making the observations. Population size, common ancestry, and juvenile development mode (nidicolous versus nidifugous, a known confound of brain size) are the avian variables that have been assessed. Among the biases on the ornithologist's side are interest for certain types of birds over others (measured by the taxonomic distribution of photographs in birding magazines), likeliness to notice and report an unusual feeding behavior in some taxa more than others (measured by a questionnaire), journal source (in Europe, British Birds versus all others; in North America, Wilson Bulletin versus all others), and historical period (e.g., pre- versus post-1960). None of these variables affect the relationship between innovation frequency and other biological traits once species number per taxon or research effort are entered in the multivariate models.

A final control for biases in birds is the study of Nicolakakis and Lefebvre [2000] on reports of unusual nesting behavior. Nesting is the third most frequently reported behavior in the short notes of avian journals, after range expansion and feeding. Contrary to opportunistic generalist foraging and sophisticated food searching techniques, there is no presumed cognitive basis for changes in nest building site or technique; in fact, the major sources in this area see nesting as predominantly pre-programmed [Hansell, 1984]. If the patterns found for feeding are due to literature biases, then these should also affect reports of unusual nesting. If cognitive differences between taxa are the key variable, then nesting should not show the same patterns as feeding. As predicted, Nicolakakis and Lefebvre [2000] found no significant relationship between relative brain size and frequency of unusual nesting reports. Innovation rate thus appears to be a reliable measure of cognition, and we now turn to addressing how this measure can be used to explore the reasons behind variation in brain size.

\section{Neural and Cognitive Correlates of Innovation in Birds}

The majority of the work on the neural and cognitive correlates of innovation rate has been conducted in birds [Lefebvre et al., 1997, 1998, 2001, 2002; Lefebvre, 2000; Timmermans et al., 2000; Lefebvre and Bolhuis, 2003]. We therefore focus on birds first and subsequently discuss commonalities in avian and primate brain evolution. A classic prediction in studies of the brain has been that larger brains or larger association areas should allow more complex cognition [Jerison, 1973]. Tests of this idea on a large number of species have proved difficult [Seyfarth and Cheney, 2002], but the use of feeding innovations in birds has provided strong support for a positive correlation between cognition and relative size of the forebrain.

To return to the example cited at the beginning of this paper, the large-brained crows (genus Corvus) yield 117 innovation reports in the zones covered by our data base, whereas the entire order that includes the smaller-brained doves (Columbiformes) yields only 13 reports for three times the number of species. Over all available bird orders and parvorders, the correlation between innovation rate (corrected for biases) and either relative size of the whole brain [data from Mlikovsky, 1989a, b, c, 1990] or of the 
forebrain [data from Portmann, 1947] is in the $r=0.5$ to 0.7 range. For neural correlates, multiple regressions are conducted at the order and parvorder level as nested ANOVA [Harvey and Pagel, 1991] shows that high taxonomic levels like the parvorder explain a higher proportion of inter-taxon variance in relative brain size than lower levels such as the family or genus. Avian phylogenetic relationships are well established at this taxonomic level [Sibley and Alquist, 1990], allowing the removal of phylogenetic effects on the relationships being tested. Comparative techniques like independent contrast analysis [Felsenstein, 1985; Harvey and Pagel, 1991] account for the fact that groups might share some characteristics because they are closely related, not because they have evolved independently under similar selection pressures; treating taxa as independent data points may then overestimate the degrees of freedom and potentially give false positive results [Purvis and Rambaut, 1995; Purvis and Webster, 1999]. Overall, the correlation between innovation rate and neural structure size (whole brain, forebrain or hyperstriatum ventrale) drops slightly when phylogeny is taken into account using independent contrasts, but remains significant. This effect is due to some closelyrelated avian taxa showing similarly high innovation rates and large brains (for example, the parvorders Corvida and Passerida, the parvorders Falconida and Accipitrida) or similarly low innovation rates and small brains (for example, the parvorders Phasianida and Odontophorida). However, the overall relationship remains significant after taking independent contrasts because some distantlyrelated taxa also combine a large brain and a high innovation rate (Piciformes, Psittaciformes, Bucerotiformes), whereas others combine a small brain with a low innovation rate (Struthioniformes, Scolopacida, Caprimulgi, Apodiformes, Columbiformes). These trends underline an important characteristic of avian evolution, the fact that large brains seem to have independently evolved at least six times in phyletically distant groups: woodpeckers (Piciformes), hornbills (Bucerotiformes), parrots (Psittaciformes), owls (infraorder Strigi), hawks and falcons (Accipitrida and Falconida) and Passeriformes (Tyranni, Corvida, Passerida), with storks, pelicans, petrels and penguins (Ciconiida) as a possible seventh group (fig. 1).

Within the avian telencephalon, the areas one would most expect to be involved in innovative behavior are the neostriatum (Neo) and hyperstriatum ventrale (HV). In a study that compared the relative size of these structures with that of two other telencephalic areas, the striatopallidal complex and wulst, the best predictor of innovation rate was found to be the $\mathrm{HV}$, closely followed by Neo (tel- encephalic data from Boire [1989] and Rehkämper et al. [1991]). The avian neostriatum and hyperstriatum ventrale play an important role in several kinds of learning [McCabe et al., 1982; Horn, 1990; Nottebohm et al., 1990; Macphail et al., 1993]. In contrast, the wulst is a sensory projection area for visual and somatosensory information [Karten et al., 1973; Shimizu et al., 1995]. The striatopallidal complex appears to control stereotyped, species-specific responses [Reiner et al., 1984; Dubbeldam, 1998]. Both the wulst and striatopallidal complex play some role in learned behavior [wulst: Macphail, 1976; Simizu and Hodos, 1989; Deng and Rogers, 1997; striatopallidal complex: Parent, 1986; Stewart et al., 1996; Mezzey et al., 1999], but they are less specialized in complex integration than are the neostriatum and hyperstriatum ventrale.

Neo and HV are also the telencephalic areas that are most closely correlated with a second cognitive measure in birds, the taxonomic distribution of tool use reports [Lefebvre et al., 2002]. The logic here is similar to the one used for innovations. Using the reviews of Boswall [1977, $1978,1983 \mathrm{a}, \mathrm{b}]$, as well as a search through the innovation data base and The Zoological Record, the taxonomic distribution of tool use reports $(n=125$ cases in 104 species from 15 orders and parvorders) was found to be most closely correlated with relative Neo volume, closely followed by HV volume. This trend holds for the two categories of tool use distinguished in the literature, 'true' tools (probes, hammers, scoops) that are detached from the substrate and directly held in the beak or foot, and 'proto' or 'borderline' tools (anvils, bait, wedges, skewers), which are not directly manipulated and not detached from the substrate. The division between borderline and true tool use has been criticized as arbitrary and unrelated to the complexity of the tasks involved [Beck, 1980]. However, brain size measures distinguish the two tool use categories. True tool users have an overall brain size that is significantly larger than proto-tool users, and the size of Neo is the closest telencephalic predictor in both true and proto-tool use, followed closely by HV. In addition to tertiary areas, the avian neostriatum includes primary projection fields from both somatosensory (nucleus basalis) and visual (ectostriatum) pathways, as well as secondary areas that receive input from these primary termination fields [Rehkämper et al., 1985]. Neo thus has the necessary features for both the cognitive and sensory-motor aspects of tool use. True tool use in particular requires a subtle coordination of visual and somatosensory information. Ascending visual pathways to the forebrain terminate in the ectostriatum, located in the core of the neostriatum, and 
Fig. 1. Mean residual brain size in birds, with the phyletic relationships between taxa taken from Sibley and Alquist [1990].
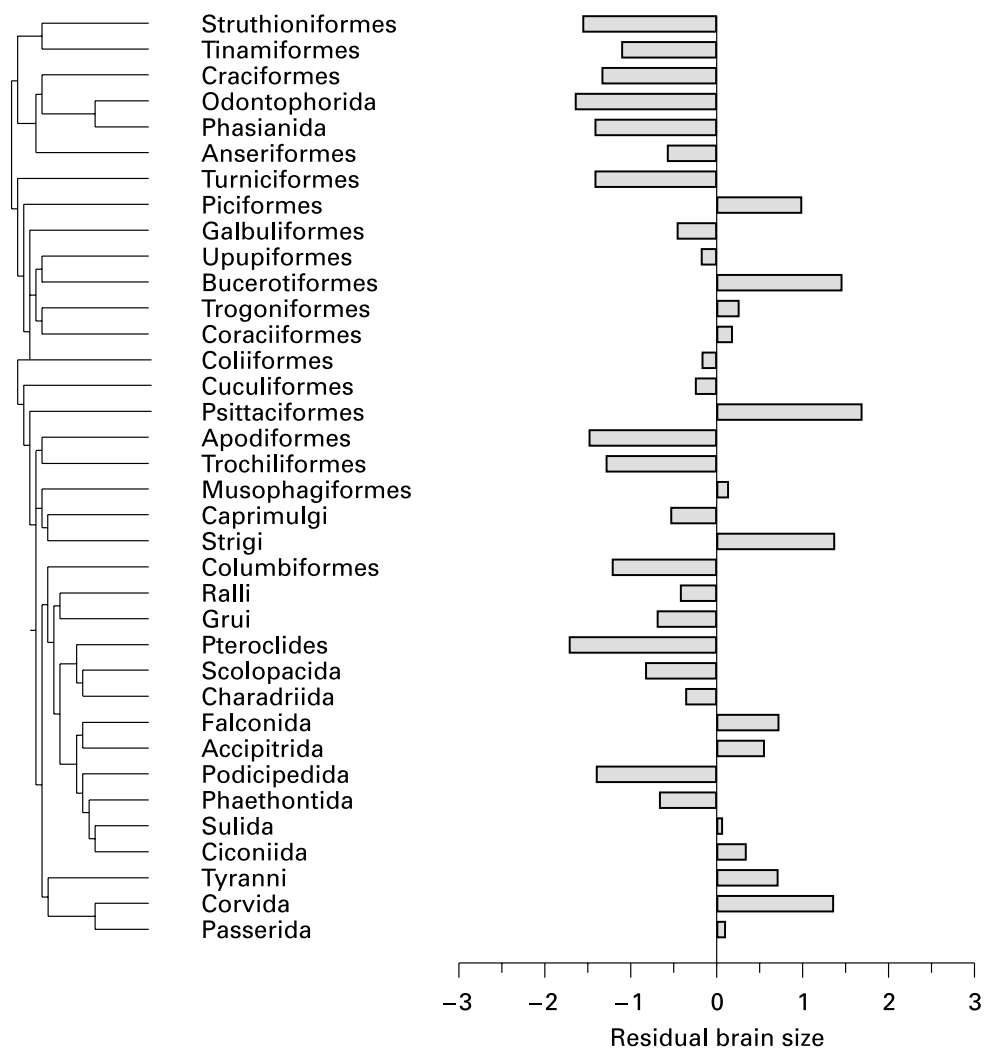

in the wulst. Sensory representation for the bill is located in the nucleus basalis prosencephali, included in the neostriatum in the data bases of Boire [1989] and Rehkämper et al. [1991].

Innovation rate (after removal of novel tool use cases included in previous publications) also correlates positively with both tool use categories [Lefebvre et al., 2002]. This correlation between innovation rate and tool use is part of a more general trend of positive association between cognitive measures [see also Lefebvre and Giraldeau, 1996; Lefebvre, 2000]. If we go back to the associative learning data of Gossette [1968] and Sasvàri [1985], positive correlations are found between innovation frequency and learning performance. In Sasvàri's study, for example, the species that learns fastest, the blackbird Turdus merula also shows the highest number of innovation reports in our data base (25). Another comparative test, of five avian species in Barbados, combined field and captive experiments and was designed to mimic innovative problem-solving as closely as possible, revealing a similar positive relationship between innovation frequency and test performance [Webster and Lefebvre, 2001]. The positive correlation between innovation rate and inter-taxon differences in captive learning tests validates the ecological assumptions of the comparative psychologists.

The only negative association that has been observed so far between innovation rate and another cognitive measure in birds involves food caching. In both North American corvids and European parids, but not in European corvids, the most innovative species tend to be the ones that cache the least [Lefebvre and Bolhuis, 2003]. These trends suggest that there might be some trade-off between caching and innovation, but not between innovation, tool use and learning.

\section{Neural and Cognitive Commonalities in Birds and Primates: A Case for Parallel Evolution?}

Here, we examine the behavioral evidence for commonalities in mammalian and avian brain evolution, focusing on innovation rate (summarized in fig. 2). We 
Fig. 2. Avian (A) and primate (B) innovation rate and (i) relative brain size (Neo-HV in birds, isocortex and striatum in primates), (ii) the frequency of reported tool use, and (iii) individual learning. Numbers indicate the taxa $(\mathbf{A})$ or species (B), to allow identification of points these data are presented rather than independent contrasts. Some points are not numbered due to space limitations. A 1: Corvida, 2: Psittaciformes, 3: Trochiliformes, 4: Ciconiida, 5: Passerida, 6: Charadriida, 7: Apodiformes, 8: Craciformes, 9: Sulida, 10: Caprimulgi, 11: Scolopacida, 12: Columbiformes, 13: Anseriformes, 14: Odontophorida, 15: Struthioniformes, 16: Phasianida, 17: Grui. B 1: Pan troglodytes, 2: Pongo pygmaeus, 3: Cebus apella, 4: Papio anubis, 5: Gorilla gorilla, 6: Macaca fuscata, 7: Papio papio, 8: Pan paniscus, 9: Cercopithecus mitis, 10: Alouatta seniculus, 11: Lemur catta, 12: Macaca mulatta 13: Saimiri sciureus, 14: Cebus albifrons, 15: Ateles geoffroyi, 16: Callithrix jacchus. Innovation data are taken from the current avian data set (see text) or from Reader and Laland [2002]. Avian brain data sources are given in the text, primate data are from Stephan et al. [1981] and Zilles and Rehkämper [1988]. Where Stephan et al. [1981] identify only the genus, the species identity was assumed to be as in Stephan et al. [1988; c.f., Reader and Laland, 2002]. B (ii) presents a reanalysis of the data from Reader and Laland [2002], excluding all species where neither innovation or tool use were reported $(\mathrm{r}=$ $0.78, \mathrm{p}<0.0001)$. Avian individual learning data are errors in reversal learning, taken from Gossette [1968; see Timmermans et al., 2000]. Primate individual learning data are laboratory learning set data from the compilation of Riddell and Corl [1977]; Spearman rank correlation, corrected for ties: $r_{s}=0.77$, $\mathrm{N}=6, \mathrm{p}_{\text {one-tailed }}=0.042$. The regression line on $\mathbf{B}$ (iii) is shown for illustration.

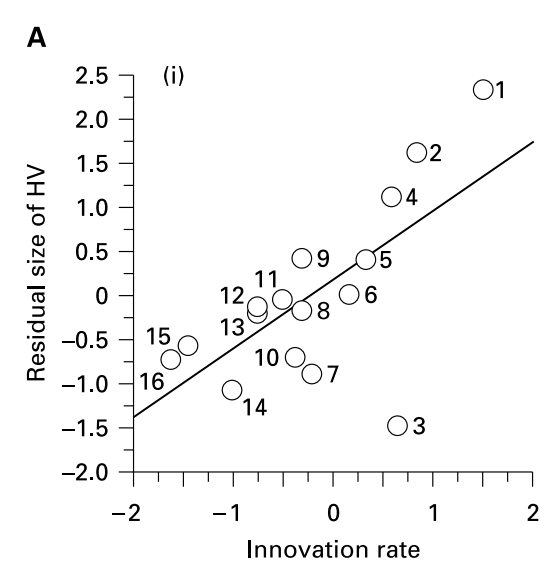

B
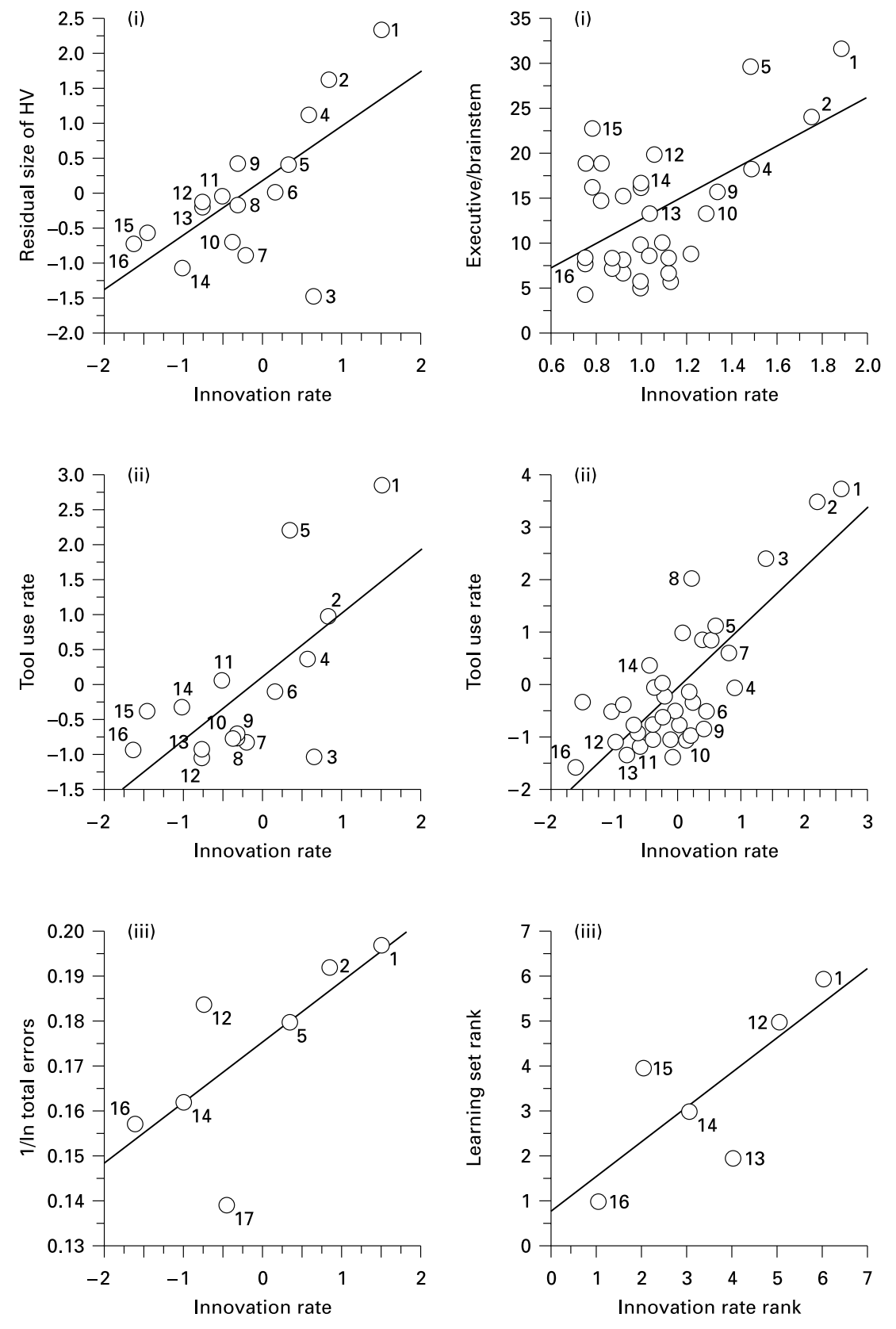

compare birds with primates [like Rehkämper et al., 1991] because this is where innovation data are available. Innovation frequency correlates with relative brain size in both birds and primates [Lefebvre et al., 1997; Reader and Laland, 2002]. Specifically, the brain areas involved in higher order and multimodal integration (isocortex and striatum in primates, hyperstriatum ventrale and neo- striatum in birds) are enlarged in taxa with high frequencies of reported novel behavior patterns, compared to groups where few innovations are reported [Timmermans et al., 2000; Reader and Laland, 2002; Reader, 2003]. Primate innovation rate also correlates with measures of individual learning, the variety of reported tool use, and the reported frequency of social learning, suggesting that 


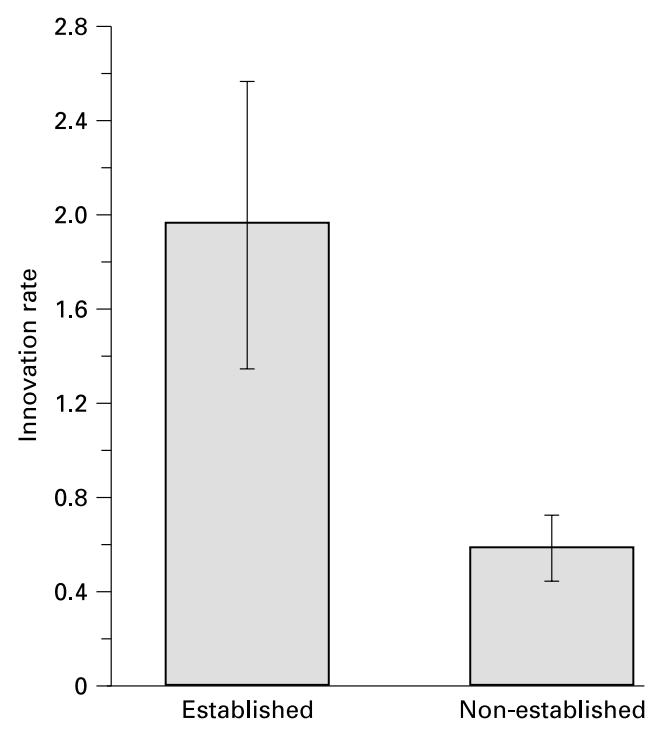

Fig. 3. Species that have been successfully introduced to New Zealand $(n=28)$ tend to be more innovative in their region of origin than those that failed to establish themselves $(n=48)$ in New Zealand [mean \pm SE; data from Sol and Lefebvre, 2000].

these cognitive capacities have evolved together [Reader and Laland, 2002]. Similarly, in birds, innovation rate correlates with laboratory measures of individual learning [Timmermans et al., 2000], and with tool use frequencies [Lefebvre et al., 2002]. The relationship between the reported frequency of social learning and innovation rate in birds is less clear [Bouchard, 2002]. This last discrepancy might reflect the difficulties in estimating species' reliances on social learning from observational reports. However, in general a similar pattern of results are observed in both primates and birds, despite the different levels of analysis utilized.

The fact that many of the trends found in birds also apply to primates suggests that the evolution of the avian and mammalian brain may have followed similar trends, particularly in the expansion of structures involved in multimodal integration capacities [Rehkämper and Zilles, 1991]. Allometric, developmental, architectonic, immunocytochemical and tracing results indicate that the neostriatum-hyperstriatum ventrale (Neo-HV) complex is the avian counterpart to the mammalian isocortex [Rehkämper et al., 1991; Rehkämper and Zilles, 1991; Waldmann and Güntürkün, 1993]. A considerable region in both the isocortex and the Neo-HV complex is occupied by tertiary integration areas, and Rehkämper and Zilles
[1991] suggest the Neo-HV complex may in fact constitute a structural and functional unit. Traditionally, the avian wulst was thought of as homologous to the mammal isocortex, but current evidence suggests otherwise [Rehkämper et al., 1991; Rehkämper and Zilles, 1991]. In both birds and mammals, the brain does not evolve as an unitary structure but instead mosaic evolution is the rule and the size of brain structures can vary independently of evolutionary changes in other brain area volumes [Eisenberg and Wilson, 1978; Kaas, 1995; Barton and Harvey, 2000; De Winter and Oxnard, 2001; but see Finlay and Darlington, 1995; Finlay et al., 2001].

\section{Ecological and Evolutionary Correlates of Innovation in Birds}

It is often assumed that innovative behaviors allow animals to adjust to novel circumstances [Lee, 1991]. The invasion of a new habitat may be one key situation where animals can benefit from innovative behavior, and we might expect innovative species to be more successful at establishing themselves in new regions than less innovative species. Recent evidence examining human introductions of birds in novel environments supports this hypothesis. In both regional- and global-scale analyses, species that tend to successfully establish themselves in new regions are more innovative in their area of origin than unsuccessful species (fig. 3) [Sol and Lefebvre, 2000; Sol et al., 2002; Sol, 2003]. These trends hold even when controlling for phylogenetic biases or other correlates of invasion success like migratory habits, sexually selected traits or the number of individuals introduced. Moreover, successful species tend to have relatively larger brains than unsuccessful species, a pattern that is again consistent at both regional and global scales [Sol and Lefebvre, 2000; Sol et al., 2002; Sol, 2003].

Innovative behavior may also provide benefits in species inhabiting seasonal environments. In temperate regions, for example, environmental conditions dramatically change with the season, the situation becoming particularly harsh in winter when temperatures are low, the days are short, and food is in short supply [Jansson et al., 1981]. Some birds avoid winter by moving to more favorable locations, whereas others are able to stay in the same regions all year long. If innovative behavior assists animals in coping with environmental changes, we might predict that more innovative species could reside the entire year in one region whereas less innovative species would be forced to migrate. Data on Western Palearctic 
passerines [Sol, unpublished observations] are consistent with this interpretation: resident species tend to be more innovative than migratory species, whether or not we control for differences in research effort devoted to the different migratory classes. Interestingly, innovations are more often reported in winter than in the remaining year [unpublished observations], consistent with the hypothesis that it is 'necessity' that prompts innovation [Laland and Reader, 1999; Reader and Laland, 2001]. Resident and migratory species also differ in brain size; resident species have larger brains, relative to body size, than migratory species [Sol, unpublished observations].

The link between innovation and changing environmental conditions has a number of ecological and evolutionary implications. For example, because extinctions are often caused by environmental change [Owens and Bennett, 2000; McLaughlin et al., 2002], one would expect that highly innovative species should be at less risk of extinction than less innovative ones. Current comparative evidence does not support this hypothesis, however [Nicolakakis et al., 2003]. Highly innovative lineages of birds contain no fewer endangered species than less innovative lineages, and the same is true when one compares large-brained and small-brained lineages. Similarly, taxonomic variation in the use of highly disturbed habitats (i.e., urban and suburban habitats) does not correspond to variation in innovation rate, although parvorders with larger relative brain volumes do tend to contain more urbanized species than small-brained parvorders [Timmermans, 1999].

Innovative propensities could promote evolutionary diversification in animals for at least two reasons. The first is related to the increased ability of innovative species to invade new environments. Species that invade new regions may diverge rapidly from ancestors through a combination of divergent natural selection, genetic drift, divergence under uniform selection, and geographic isolation interrupting gene flow with ancestors [Baker and Moeed, 1987; Hendry et al., 2000]. The second reason is that an innovative propensity (e.g., for novel foraging techniques) could increase the chance of that species entering new adaptive zones, and hence exposure to divergent natural selection [Wyles et al., 1983]. However, theoreticians also predict the contrary result, that is, a reduction instead of an increase in the rate of evolution in species with high ability for behavioral change [Lynch, 1990; Robinson and Dukas, 1999]. The strength of natural selection might for example be reduced if individuals tend to respond to new ecological challenges by means of behavioral modifications rather than through heritable variation [Robinson and Dukas, 1999]. Evidence to date appears to favor an association between innovation and increased evolutionary diversification [but see Lynch, 1990]. Species-rich parvorders tend to be more innovative, after adjusting for differences in research effort, and have larger brains than species-poor parvorders [Nicolakakis et al., 2003].

Despite the trend for increased number of species in innovative lineages, many species thrive while showing relatively low rates of innovation. Innovative propensities are unlikely to be beneficial in all ecological contexts or environmental conditions as innovation is likely to carry a number of costs. Obvious costs are the time expenditure or risks incurred in the discovery of a novel behavior pattern, compared with an established behavior [Bandura, 1977; Johnston, 1982]. Less obvious costs include slower developmental rates and the high energetic demands of the enlarged brains that accompany high innovation rates. It is well established that brain tissue is metabolically expensive [Armstrong, 1983; Aiello and Wheeler, 1995], and larger brains require elongated developmental periods [Bennett and Harvey, 1985b; Finlay and Darlington, 1995; Ricklefs, 1998]. Thus the large-brained individual pays both an energetic and an ontogenic cost. In addition to these costs, there might also be a number of constraints on behavioral innovation. For example, species with morphological specializations for particular resource types may be limited in their innovative adoption of alternative resources. Similarly, ancestral life history traits or dietary requirements might constrain the evolution of innovative propensities in certain species. For example, obligate leafeaters may be unable to bear the energetic costs of a large brain [Aiello and Wheeler, 1995]. It is clear that more work needs to be done, particularly on the psychological processes and environmental circumstances favoring innovation, but the innovation framework may provide a valuable opportunity to examine the costs and constraints acting on the evolution of complex cognitive abilities and enlarged brains.

\section{Conclusion}

Our focus on innovative behavior is similar to the approach proposed by Johnston [1981, 1982] two decades ago. Both approaches emphasize flexible behavior in the natural environment and frame their predictions in a comparative, cost/benefit logic. When Johnston [1981] published his plea for an ecological theory of learning, some commentators like Rachlin [1981] expressed their 
doubts in a rather robust manner. 'Natural environment', like 'natural underarm deodorant', wrote Rachlin [1981; pp. 155-156] 'is a term appropriate to advertising, not science... I wish Johnston the best of luck if and when he begins to create a general theory of learning from the mass of casual observation... and theoretical guesswork that goes by the name of ethological research'. Despite such skepticism, we are optimistic that 'the mass of casual observation' in our innovation databases offers a useful, ecologically valid way of quantifying cognitive differences in birds and primates.

The innovation approach suggests several tentative answers to the questions raised at the start of this review. (1) How can we quantify animal cognition in a large number of species? By counting innovations in the field, an operational measure that corresponds quite closely to the results of captive tests. (2) Did cognitive capacities evolve independently? Several cognitive measures correlate positively with innovation rate in both birds and primates, suggesting that they are all part of a general problem-solving ability or that they have evolved together; only foodcaching in birds appears to be traded-off against this set of cognitive measures. (3) What are the links between brain architecture and cognition? Large brain areas like the mammalian isocortex and the avian neostriatum and hyperstriatum ventrale correlate with innovation, tool use and learning differences between taxa. (4) What are the benefits of enlarged brains? Innovative, large-brained avian species appear to cope better with seasonal changes and the novel circumstances that accompany biological invasions. (5) What are the costs and constraints of innovativeness? Innovations may be limited by dietary or oth- er constraints in certain taxa; the energetic and developmental demands of a larger brain might also counteract the benefits of innovation in some groups. (6) What are the evolutionary consequences of innovation? The fact that innovative avian taxa tend to show more species per parvorder supports the hypothesis that behavioral innovation is one factor enhancing the rate of evolution in animals.

The innovation approach has allowed us to test a broad set of hypotheses on the evolutionary ecology of brains and cognition. Most of our tests support the predictions, with the exception of urbanization and vulnerability to extinction. Invasion success, evolutionary diversification, cognitive measures like tool use and associative learning, as well as relative size of the brain and its main integrative areas are all associated with innovation rate. Except for the uncertain result on social learning in birds, the parallel results on innovation, tool use, learning, the mammalian isocortex and the avian Neo-HV complex suggest a striking pattern of convergent evolution between primates and birds. Similar solutions to brain-cognition organization seem to have evolved in the two groups, whose ancestors diverged more than 300 million years ago. In birds, large brains appear to have independently co-evolved with innovative behavior at least six times in widely divergent taxa: Piciformes, Accipitrida and Falconida, Bucerotiformes, Psittaciformes, Ciconiida and Passeriformes (especially Corvida. Combined with the results of the comparative approaches summarized earlier, the data provide strong evidence for evolutionary links between ecology, cognition, and brain architecture.

\section{References}

Aiello L, Wheeler P (1995) The expensive-tissue hypothesis: the brain and the digestive system in human and primate evolution. Curr Anthropol 36:199-221.

Alp R (1997) 'Stepping-sticks' and 'seat-sticks': new types of tools used by wild chimpanzees (Pan troglodytes) in Sierra Leone. Am J Primatol 41: 45-52.

Armstrong E (1983) Relative brain size and metabolism in mammals. Science 220:1302-1304.

Baker AJ, Moeed A (1987) Rapid genetic differentation and founder effects in colonizing populations of common mynas (Acridotheres tristis). Evolution 41:525-538.

Balda RP, Kamil AC (1989) A comparative study of cache recovery by three corvid species. Anim Behav 38:486-495.
Bandura A (1977) Social Learning Theory. New Jersey: Prentice-Hall.

Barton R (1999) The evolutionary ecology of the primate brain. In: Comparative Primate Socioecology (Lee PC, ed), pp 167-194. Cambridge UK: Cambridge University Press.

Barton RA (1996) Neocortex size and behavioural ecology in primates. Proc R Soc Lond B 263: 173-177.

Barton RA, Dunbar RIM (1997) Evolution of the social brain. In: Machiavellian Intelligence II (Whiten A, Byrne RW, eds), pp 240-263. Cambridge UK: Cambridge University Press.

Barton RA, Harvey PH (2000) Mosaic evolution of brain structure in mammals. Nature 405: 1055-1058.

Basil JA, Kamil AC, Balda RP, Fite KV (1996) Differences in hippocampal volume among food storing corvids. Brain Behav Evol 47:156-164.
Beck BB (1980) Animal Tool Behavior: The Use and Manufacture of Tools by Animals. New York: Garland.

Bennett PM, Harvey PH (1985b) Brain size, development and metabolism in birds and mammals. J Zool 207:491-509.

Bennett PM, Harvey PH (1985a) Relative brain size and ecology in birds. J Zool 207:151-169.

Bennett PM, Owens IPF (2002) Evolutionary Ecology of Birds: Life Histories, Mating Systems and Extinction. Oxford UK: Oxford University Press

Boire D (1989) Comparaison quantitative de l'encéphale, de ses grandes subdivisions et de relais visuels, trijumaux et acoustiques chez 28 espèces d'oiseaux. PhD dissertation, Université de Montréal, Montréal, Canada. 
Bolhuis JJ, Macphail EM (2001) A critique of the neuroecology of learning and memory. Trends Cogn Sci 5:426-433.

Boswall J (1977) Tool-using by birds and related behaviour. Avicult Mag 83:88-97, 146-159, 220-228.

Boswall J (1978) Further notes on tool-using in birds and related behaviour. Avicult Mag 84: 162-166.

Boswall J (1983a) Tool-using and related behaviour in birds: more notes. Avicult Mag 89:94-108.

Boswall J (1983b) Tool-using and related behaviour in birds: yet more notes. Avicult Mag 89: 170-181.

Bouchard J (2002) Is social learning correlated with innovation in birds? An inter- and an interspecific test. M.Sc. dissertation, McGill University, Montreal, Canada.

Box HO, Gibson KR (eds) (1999) Mammalian Social Learning: Comparative and Ecological Perspectives. Cambridge UK: Cambridge University Press.

Byrne RW (1993) Do larger brains mean greater intelligence? Behav Brain Sci 16:696-697.

Byrne RW, Whiten A (1990) Tactical deception in primates: the 1990 data-base. Primate Rep 27: $1-101$.

Child P (1978) Yellowhead not entirely insectivorous. Notornis 25:252-253.

Clutton-Brock TH, Harvey PH (1980) Primates, brain and ecology. J Zool Lond 190:309-323.

Day LB, Crews D, Wilczynski W (1999a) Relative medial and dorsal cortex volume in relation to foraging ecology in congeneric lizards. Brain Behav Evol 54:314-322.

Day LB, Crews D, Wilczynski W (1999b) Spatial and reversal learning in congeneric lizards with different foraging strategies. Anim Behav 57: 393-407.

De Winter W, Oxnard CE (2001) Evolutionary radiations and convergences in the structural organization of mammalian brains. Nature 409:710-714.

Deaner RO, Nunn CL, van Schaik CP (2000) Comparative tests of primate cognition: different scaling methods produce different results. Brain Behav Evol 55:44-52.

Deng C, Rogers LJ (1997) Differential contributions of the two visual pathways to functional lateralization in chicks. Behav Brain Res 87: 173-182.

DeVoogd TJ, Krebs JR, Healy SD, Purvis A (1993) Relations between song repertoire size and the volume of brain nuclei related to song: Comparative evolutionary analyses amongst oscine birds. Proc R Soc Lond B 254:75-82.

DeVoogd TJ (2004) Neural constraints on the complexity of avian song. Brain Behav Evol 63: 221-232.

Dubbeldam JL (1998) Birds. In: The Central Nervous System of Vertebrates (Nieuwenhuys R, TenDonkelaar HJ, Nicholson C, eds), pp 1525-1620. Berlin: Springer Verlag.

Dunbar RIM (1992) Neocortex size as a constraint on group size in primates. J Hum Evol 20:469493.

Dunbar RIM (1995) Neocortex size and group size in primates: a test of the hypothesis. J Hum Evol 28:287-296.
Dunbar RIM (1998) The social brain hypothesis. Evol Anthropol 6:178-190.

Dunbar RIM, Bever J (1998) Neocortex size determines group size in carnivores and some insectivores. Ethology 104:695-708.

Eisenberg JF, Wilson DE (1978) Relative brain size and feeding strategies in the chiroptera. Evolution 32:740-751.

Felsenstein J (1985) Phylogenies and the comparative method. Am Nat 125:1-15.

Finlay BL, Darlington RB (1995) Linked regularities in the development and evolution of mammalian brains. Science 268:1578-1584.

Finlay BL, Darlington RB, Nicastro N (2001) Developmental structure in brain evolution. Behav Brain Sci 24:263-308.

Fisher J, Hinde RA (1949) The opening of milk bottles by birds. Brit Birds 42:347-357.

Fragaszy DM, Perry S (eds) (2003) The Biology of Traditions: Models and Evidence. Cambridge UK: Cambridge University Press.

Gittleman JL (1986) Carnivore brain size, behavioural ecology, and phylogeny. J Mammal 67: 23-36.

Gittleman JL (1994) Female brain size and parental care in carnivores. Proc Nat Acad Sci USA 91:5495-5497.

Gossette RL (1968) Examination of retention decrement explanation of comparative successive discrimination reversal learning by birds and mammals. Percept Motor Skills 27:11471152.

Gould-Beierle KL (2000) A comparison of four corvid species in a working and reference memory task using a radial maze. J Comp Psychol 114: 347-356.

Hampton RR, Sherry DF, Shettleworth SJ, Khurgel M, Ivy G (1995) Hippocampal volume and food-storing behaviour are related in parids. Brain Behav Evol 45:54-61.

Hansell MH (1984) Animal Architecture and Building Behaviour. London: Longman.

Harvey PH, Clutton-Brock TH, Mace GM (1980) Brain size and ecology in small mammals and primates. Proc Nat Acad Sci USA 77:43874389.

Harvey PH, Pagel MD (1991) The Comparative Method in Evolutionary Biology. Oxford UK: Oxford University Press.

Healy SD, Hurly TA (2004) Spatial learning and memory in birds. Brain Behav Evol 63:211220.

Healy SD, Krebs JR (1992) Food storing and the hippocampus in corvids: amount and volume are correlated. Proc R Soc Lond B 248:241245.

Healy SD, Krebs JR (1996) Food storing and the hippocampus in Paridae. Brain Behav Evol 47: 195-199.

Hendry AP, Wenburg JK, Bentzen P, Volk EC, Quinn TP (2000) Rapid evolution of reproductive isolation in the wild: evidence from introduced salmon. Science 290:516-518.

Heyes CM, Galef BG, Jr. (1996) Social Learning in Animals: The Roots of Culture. London UK: Academic Press.

Horn G (1990) Neural bases of recognition memory investigated through an analysis of imprinting. Phil Trans R Soc Lond B 329:133-142.
Huber R, van Staaden MJ, Kaufman LS, Liem KF (1997) Microhabitat use, trophic patterns, and the evolution of brain structure in African cichlids. Brain Behav Evol 50:167-182.

Iwaniuk A, Nelson J, Pellis S (2001) Do big-brained animals play more? J Comp Psychol 115:2941.

Jacobs LF, Spencer WD (1994) Natural space-use patterns and hippocampal size in kangaroo rats. Brain Behav Evol 44:125-132.

Jacobs LF, Gaulin SJC, Sherry DF, Hoffman GE (1990) Evolution of spatial cognition: sex-specific patterns of spatial behavior predict hippocampal size. Proc Nat Acad Sci USA 87:63496352.

Jansson C, Ekman J, von Brömssen A (1981) Winter mortality and food supply in tits Parus spp. Oikos 37:313-322.

Jerison HJ (1973) Evolution of the Brain and Intelligence. New York: Academic Press.

Johnston TD (1981) Contrasting approaches to a theory of learning. Brain Behav Sci 4:125-173.

Johnston TD (1982) The selective costs and benefits of learning: an evolutionary analysis. Adv Study Behav 12:65-106.

Jolicoeur P, Pirlot P, Baron G, Stephan H (1984) Brain structure and correlation patterns in insectivora, chiroptera, and primates. Syst Zool 33:14-29.

Kaas JH (1995) The evolution of isocortex. Brain Behav Evol 46:187-196.

Kaas JH (2002) Convergences in the modular and areal organization of the forebrain of mammals: implications for the reconstruction of forebrain evolution. Brain Behav Evol 59:262272.

Kabai P (2001) Modular evolution of avian brain areas. Behaviour plasticity in birds. Hungarian Acad Sci Budapest.

Kamil AC (1988) A synthetic approach to the study of animal intelligence. In: Comparative Perspectives in Modern Psychology. Nebraska Symposium of Motivation (Volume 35) (Leger DW, ed), pp 257-388. Lincoln, NB: University of Nebraska Press.

Karten HJ, Hodos W, Nauta WJH, Revzin AM (1973) Neural connections of the 'visual Wulst' of the avian telencephalon. Experimental studies in the pigeon and owl. Comp Neurol 150 253-278.

Kawai M (1965) Newly-acquired pre-cultural behavior of the natural troop of Japanese monkeys on Koshima Islet. Primates 6:1-30.

Krebs JR, Sherry DF, Healy SD, Perry H, Vaccerino AL (1989) Hippocampal specialization of food-storing birds. Proc Nat Acad Sci USA 86: 1388-1392.

Kudo H, Dunbar RIM (2001) Neocortex size and social network size in primates. Anim Behav 62:711-722.

Laland KN, Reader SM (1999) Foraging innovation in the guppy. Anim Behav 57:331-340.

Lee P (1991) Adaptations to environmental change: An evolutionary perspective. In: Primate Responses to Environmental Change (Box HO, ed), pp 39-56. London UK: Chapman and Hall. 
Lefebvre L (2000) Feeding innovations and their cultural transmission in bird populations. In: The Evolution of Cognition (Heyes C, Huber L, eds), pp 311-328. Cambridge MA: MIT Press.

Lefebvre L, Bolhuis JJ (2003) Positive and negative correlates of feeding innovations in birds: evidence for limited modularity. In: Animal Innovation (Reader SM, Laland KN, eds), pp 4061. Oxford UK: Oxford University Press.

Lefebvre L, Giraldeau L-A (1996) Is social learning an adaptive specialization? In: Social Learning in Animals: the Roots of Culture (Heyes CM, Galef, Jr BG, eds), pp 107-128. London UK: Academic Press.

Lefebvre L, Gaxiola A, Dawson S, Timmermans S, Rosza L, Kabai P (1998) Feeding innovations and forebrain size in Australasian birds. Behaviour 135:1077-1097.

Lefebvre L, Juretic N, Timmermans S, Nicolakakis $\mathrm{N}$ (2001) Is the link between forebrain size and feeding innovations caused by confounding variables? A study of Australian and North American birds. Anim Cog 4:91-97.

Lefebvre L, Nicolakakis N, Boire D (2002) Tools and brains in birds. Behaviour 139:939-973.

Lefebvre L, Whittle P, Lascaris E, Finkelstein A (1997) Feeding innovations and forebrain size in birds. Anim Behav 53:549-560.

Lynch M (1990) The rate of morphological evolution in mammals from the standpoint of the neutral expectation. Am Nat 136:727-741.

Mace GM, Harvey PH, Clutton-Brock TH (1981) Brain size and ecology in small mammals. J Zool Lond 193:333-354.

Macphail EM (1976) Effects of hyperstriatal lesions on within-day serial reversal performance in pigeons. Physiol Behav 16:529-536.

Macphail EM (1982) Brain and Intelligence in Vertebrates. Oxford UK: Clarendon Press.

Macphail EM (1985) Vertebrate intelligence: the null hypothesis. Phil Trans R Soc Lond B 308: 37-51.

Macphail EM, Bolhuis JJ (2001) The evolution of intelligence: adaptive specializations versus general process. Biol Rev 76:341-364.

Macphail EM, Reilly S, Good M (1993) Lateral hyperstriatal lesions disrupt simultaneous, but not successive conditional discrimination learning of pigeons (Columba livia). Behav Neurosci 107:289-298.

Madden J (2001) Sex, bowers and brains. Proc R Soc Lond B 268:833-838.

Marino L (1996) What can dolphins tell us about primate evolution? Evol Anthropol 5:81-88.

Martin PR, Bateson P (1993) Measuring Behaviour: An Introductory Guide, 2nd edition. Cambridge UK: Cambridge University Press.

McCabe BJ, Cipolla-Neto J, Horn G, Bateson PPG (1982) Amnesic effects of bilateral lesions placed in the hyperstriatum ventrale of the chick after imprinting. Exp Brain Res 45:1321.

McLaughlin JF, Hellmann JJ, Boggs CL, Ehrlich PR (2002) Climate change hastens population extinctions. Proc Nat Acad Sci USA 99:60706074
Mezzey S, Szekely AD, Bourne RC, Kabai P, Csillag A (1999) Changes in binding to muscarinic and nicotinic cholinergic receptors in the chick telencephalon following passive avoidance learning. Neurosci Lett 270:75-78.

Mlikovsky J (1989a) Brain size in birds: 1. Tinamiformes through ciconiiformes. Vest Cs Spolec Zool 53:33-47.

Mlikovsky J (1989b) Brain size in birds: 2. Falconiformes through gaviiformes. Vest Cs Spolec Zool 53:200-213.

Mlikovsky J (1989c) Brain size in birds: 3. Columbiformes through piciformes. Vest Cs Spolec Zool 53:252-264.

Mlikovsky J (1990) Brain size in birds: 4. Passeriformes. Acta Soc Zool Bohemoslov 54:27-37.

Nealen PM, Ricklefs RE (2001) Early diversification of the avian brain:body relationship. J Zool 253:391-404.

Nicolakakis N, Lefebvre L (2000) Forebrain size and innovation rate in European birds: feeding, nesting and confounding variables. Behaviour 137:1415-1429.

Nicolakakis N, Lefebvre L, Sol D (2003) Behavioural flexibility predicts species richness in birds, but not extinction risk. Anim Behav 5: 445-452.

Nottebohm F (1981) A brain for all seasons: cyclical anatomical changes in song control nuclei of the canary brain. Science 214:1368-1370.

Nottebohm F, Alvarez-Buylla A, Ccynx JK, Ling CY, Nottebohm M, Suter R, Tolles A, Williams $H$ (1990) Song learning in birds: the relation between perception and production. Phil Trans R Soc Lond 329:115-124.

Oda R (1996) Predation on a chameleon by a ringtailed lemur (Lemur catta) in the Berenty Reserve, Madagascar. Folia Primatol 67:40-43.

Owens IPF, Bennett PM (2000) Ecological basis of extinction risk in birds: Habitat loss versus human persecution and introduced predators. Proc Nat Acad Sci USA 97:12144-12148.

Parent A (1986) Comparative Neurobiology of the Basal Ganglia. New York: John Wiley and Sons.

Plowright CMS, Reid S, Kilian T (1998) Finding hidden food: behavior on visible displacement tasks by mynahs (Gracula religiosa) and pigeons (Columba livia). J Comp Psychol 112: $13-25$.

Portmann A (1947) Etude sur la cérébralisation chez les oiseaux II. Alauda 15:1-15.

Powell RW (1974) Comparison of differential reinforcement of low rates (DRL) performance in pigeons (Columba livia) and crows (Corvus brachyrhynchos). J Comp Physiol Psychol 86: 736-746.

Purvis A, Rambaut A (1995) Comparative analysis by independent contrasts (CAIC): an Apple Macintosh application for analysing comparative data. Comp Appl Biosci 11:247-251.

Purvis A, Webster AJ (1999) Phylogentically independent comparisons and primate phylogeny. In: Comparative Primate Socioecology (Lee PC, ed), pp 44-70. Cambridge UK: Cambridge University Press.

Rachlin H (1981) Learning theory in its niche. Behav Brain Sci 4:155-156.
Reader SM (2003) Relative brain size and the distribution of innovation and social learning across the nonhuman primates. In: The Biology of Traditions: Models and Evidence (Fragaszy DM, Perry S, eds), pp 56-93. Cambridge UK: Cambridge University Press.

Reader SM, Laland KN (2001) Primate innovation: sex, age and social rank differences. Int $\mathrm{J}$ Primatol 22:787-805.

Reader SM, Laland KN (2002) Social intelligence, innovation and enhanced brain size in primates. Proc Nat Acad Sci USA 99:4436-4441.

Reboreda JC, Clayton NS, Kacelnik A (1996) Species and sex differences in hippocampus size in parasitic and non-parasitic cowbirds. NeuroReport 7:505-508.

Rehkämper G, Zilles K (1991) Parallel evolution in mammalian and avian brains: comparative cytoarchitectonic and cytochemical analysis. Cell Tissue Res 263:3-28.

Rehkämper G, Frahm HD, Zilles K (1991) Quantitative development of brain and brain structure in birds (Galliformes and Passeriformes) compared to that in mammals (insectivores and primates). Brain Behav Evol 37:125-143.

Rehkämper G, Zilles K, Schleicher A (1985) A quantitative approach to cytoarchitectonics. X. The areal pattern of the neostriatum in the domestic pigeon, Columba livia f.d. A cyto- and myeloarchitectonic study. Anat Embryol 171: 345-355.

Reiner A, Brauth SE, Karten HJ (1984) Evolution of the amniote basal ganglia. Trends Neurosci 7:320-325.

Ricklefs RE (1998) Avian Growth and Development: Evolution within the Altricial-Precocial Spectrum. New York: Oxford University Press.

Riddell WI (1979) Cerebral indices and behavioral differences. In: Development and Evolution of Brain Size: Behavioral Implications (Hahn ME, Jenson C and Dudek BC, eds), pp 89-109. New York: Academic Press.

Riddell WI, Corl KG (1977) Comparative investigation of the relationship between cerebral indices and learning abilities. Brain Behav Evol 14:385-398.

Robinson BW, Dukas R (1999) The influence of phenotypic modifications on evolution: the Baldwin effect and modern perspectives. Oikos 85:582-589.

Sasvàri L (1979) Observational learning in great, blue and marsh tits. Anim Behav 27:767-771.

Sasvàri L (1985) Different observational learning capacity in juvenile and adult individuals of congeneric bird species. Z Tierpsychol 69:293304.

Seyfarth RM, Cheney DL (2002) What are big brains for? Proc Nat Acad Sci USA 99:41414142 .

Sherry DF, Schacter DL (1987) The evolution of multiple memory systems. Psychol Rev 94: 439-454.

Sherry DF, Vaccarino AL, Buckenham K, Herz RS (1989) The hippocampal complex of food-storing birds. Brain Behav Evol 34:308-317.

Shimizu T, Cox K, Karten HJ (1995) Intratelencephalic projections of the visual wulst in pigeons (Columba livia). J Comp Neurol 359:551-572. 
Shimizu T, Hodos W (1989) Reversal learning in pigeons: effects of selective lesions of the wulst. Behav Neurosci 103:262-272.

Sibley GC, Alquist JE (1990) Phylogeny and Classification of Birds: A Study in Molecular Evolution. New Haven CT: Yale University Press.

Sol D (2003) Behavioural flexibility: a neglected issue in the ecological and evolutionary literature? In: Animal Innovation (Reader SM, Laland KN, eds), pp 63-82. Oxford UK: Oxford University Press.

Sol D, Lefebvre L (2000) Behavioural flexibility predicts invasion success in birds introduced to New Zealand. Oikos 90:599-605.

Sol D, Lefebvre L, Timmermans S (2002) Behavioural flexibility and invasion success in birds. Anim Behav 63:495-502.

Stephan H, Baron G, Frahm H (1988) Comparative size of brain and brain components. In Comparative Primate Biology, vol. 4, Neuroscience (Erwin J, Steklis HD, eds), pp 1-38. New York: Liss.
Stephan H, Frahm H, Baron G (1981) New and revised data on volumes of brain structure in insectivores and primates. Folia Primatol 35: $1-29$.

Stewart MG, Kabai P, Harrison E, Steele RJ, Kossut M, Csillag A (1996) The involvement of dopamine in the striatum in passive avoidance training in the chick. Neuroscience 70:7-14.

Thorndike EL (1911) Animal Intelligence. New York: Macmillan.

Timmermans S (1999) Opportunism and the neostriatal/hyperstriatum ventrale complex in birds. M.Sc. dissertation, McGill University, Montréal, Canada.

Timmermans S, Lefebvre L, Boire D, Basu P (2000) Relative size of the hyperstriatum ventrale is the best predictor of feeding innovation rate in birds. Brain Behav Evol 56:196-203.

Waldmann C, Güntürkün O (1993) The dopaminergic innervation of the pigeon caudolateral forebrain - immunocytochemical evidence for a prefrontal cortex in birds. Brain Res 600: 225-234

Webster SJ, Lefebvre L (2001) Problem solving and neophobia in a Columbiforme - Passeriforme assemblage in Barbados. Anim Behav 62:2332 .
Whiten A, Byrne RW (1988) Tactical deception in primates. Behav Brain Sci 11:233-273.

Wilson B, Boakes RA (1985) A comparison of the short-term memory performances of pigeons and jackdaws. Anim Learn Behav 13:285290.

Wilson B, Mackintosh NJ, Boakes RA (1985) Transfer of relational rules in matching and oddity learning by pigeons and corvids. Q J Exp Psychol 37B:313-332.

Wyles JS, Kunkel JG, Wilson AC (1983) Birds, behaviour, and anatomical evolution. Proc Nat Acad Sci USA 80:4394-4397.

Young HG (1987) Herring gull preying on rabbits. Brit Birds 80:630.

Zentall TR, Galef BG, Jr. (eds) (1988) Social Learning: Psychological and Biological Perspectives. Hillsdale NY: Erlbaum.

Zilles K, Rehkämper G (1988) The brain, with special reference to the telencephalon. In: OrangUtan Biology (Schwartz JH, ed), pp 157-176. Oxford UK: Oxford University Press. 